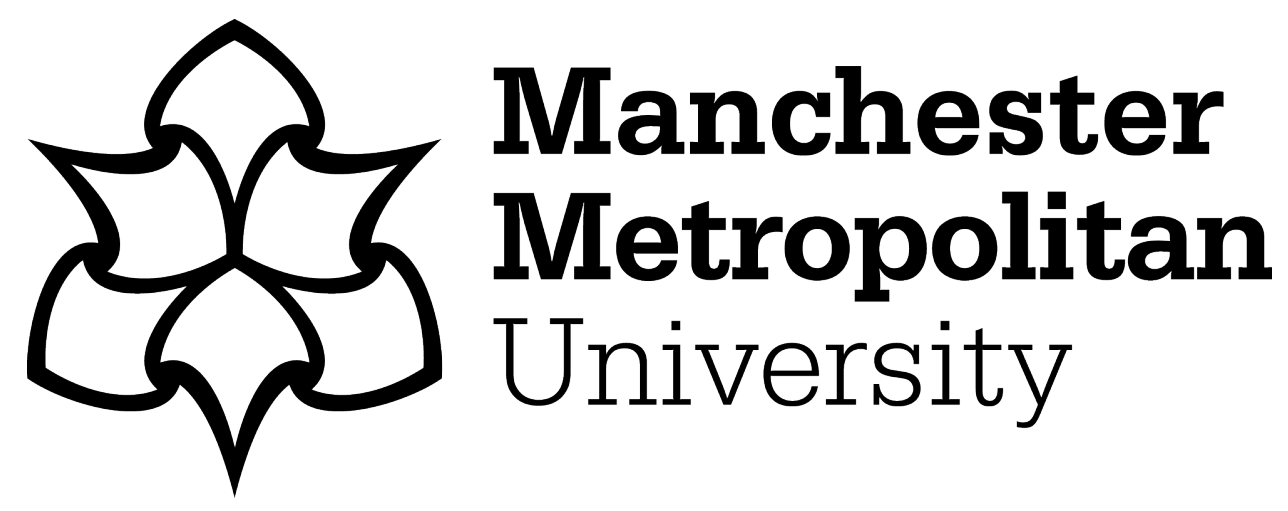

McChesney, G and Toseeb, U (2018) Happiness, Self-Esteem, and Prosociality in Children with and without Autism Spectrum Disorder: Evidence from a UK Population Cohort Study. Journal of Autism and Developmental Disorders, 11 (7). pp. 1011-1023. ISSN 1573-3432

Downloaded from: https://e-space.mmu.ac.uk/617482/

Publisher: Springer Verlag (Germany)

DOI: https://doi.org/10.1002/aur.1957

Please cite the published version 


\title{
Happiness, Self-Esteem, and Prosociality in Children with and without Autism Spectrum Disorder: Evidence from a UK Population Cohort Study
}

\author{
Gillian McChesney (1) U Toseeb
}

\begin{abstract}
High levels of childhood happiness, self-esteem, and prosociality are associated with positive social and emotional outcomes. Little is known about whether these constructs co-occur and how levels of co-occurrence are different in children with or without Autism Spectrum Disorder (ASD). Data was obtained from 13,285 11-year olds (408 with ASD) from a UK based prospective cohort study. Latent class analysis revealed five distinct classes: The "very low prosociality class" (with ASD 32\% vs. without ASD 7\%) was characterized by children who were happy and had high self-esteem but they were not prosocial. The "low happiness class" (with ASD 3\% vs. without ASD 3\%), included those children who had moderate self-esteem and were prosocial but were the least happy. Children in the "low to moderate positive functioning class" (with ASD 16\% vs. without ASD 6\%) were moderately happy and had the lowest selfesteem but were prosocial. The "moderate to high positive functioning class" (with ASD 17\% vs. without ASD 23\%) was characterized by children who were happy, had moderate self-esteem, and were very prosocial. The majority of children were in the "optimum class" (with ASD 31\% vs. without ASD 62\%), and were very happy, very prosocial with high self-esteem. Our findings demonstrate that for the majority of children in our sample, happiness, selfesteem, and prosociality co-occur. Furthermore, although as a group children with ASD have lower levels of positive functioning, our multivariable latent class approach suggests that nearly half of children with ASD are happy, have good levels self-esteem, and are prosocial. Autism Res 2018, 11: 1011-1023. () 2018 International Society for Autism Research, Wiley Periodicals, Inc.
\end{abstract}

Lay Summary: High levels of childhood happiness, self-esteem, and prosociality are associated with positive social and emotional outcomes. In this study, we investigated whether happiness, self-esteem and prosociality co-occur in children, and how possible co-occurrence differs between those with and without Autism Spectrum Disorder. We found that for the majority of children happiness, self-esteem, and prosociality co-occur. Furthermore, although as a group children with ASD have lower levels of positive functioning, our findings suggest that nearly half of children with ASD are happy, have good levels of self-esteem, and are prosocial.

Keywords: Autism spectrum disorder; happiness; prosociality; self-esteem

\section{Introduction}

Autism Spectrum Disorder (ASD) is characterized by social and communication related difficulties, problems with understanding nonverbal cues, being highly dependent on routines, and increased sensitivity to changes (APA, 2013). In the UK, by middle childhood the prevalence of ASD has been estimated at $\sim 1 \%$ (Baird et al., 2006) but it may be as high as 3.5\% (Dillenburger, Jordan, McKerr, \& Keenanm, 2015). ASD is associated with a number of co-morbidities such as emotional difficulties, depression, stress and anxiety, social anxiety, and behavioral difficulties and disorders (Green, McGinnity, Meltzer, Ford, \& Goodman, 2005;
Gurney, McPheeters, \& Davis, 2006; Matson, \& NebelSchwalm, 2007; Oyane \& Bjorvatn, 2005; van Steensel, Bogels, \& Perrin, 2011; Williams, Sears, \& Allard, 2004). The disorder is also associated with substantial costs, such as special education needs services and loss of productivity in parental workplaces (Buescher, Cidav, Knapp, \& Mandell, 2014).

\section{Self-Esteem}

Self-esteem refers to a person's confidence in their own worth or abilities and can be measured using a variety of questionnaire scales. These range from single item scales, where participants respond to one question such as "I see myself as someone who has high self-esteem", 
(Single-Item Self-Esteem Scale; Robins, Hendin, \& Trzesniewski, 2001), to the widely used Rosenberg SelfEsteem Scale (Rosenberg, 1965), where participants respond to a number of items. Such self-report measures have previously been used to assess aspects of selfesteem in children with Autism Spectrum Disorder (Williamson, Craig, \& Slinger, 2008).

Young children usually have very high self-esteem and this may be because they do not yet possess the ability to engage in the process of self-evaluation, which protects them from thinking negatively about themselves (Harter, 2012). Relatively speaking, selfesteem peaks in preadolescence after which it begins a downward trend (Robins, Trzesniewski, Tracy, Gosling, $\&$ Potter, 2002). The processes behind identity formation and physical changes to the body are also thought to be related to this drop in self-esteem during adolescence (Ricciardelli \& Yager, 2016).

Evidence suggests that low self-esteem may also have a detrimental effect on other areas of psychopathological development. Some children with low self-esteem have more conduct problems and higher levels of depression and anxiety (Ha, Petersen, \& Sharp, 2008; Moksnes, \& Espnes, 2012; Orth, \& Robins, 2014; Robins, Donnellan, Widaman, \& Conger, 2010). Low self-esteem during childhood can have long lasting negative effects. For example, some children with low self-esteem go on to be adults with poorer mental and physical health, more criminal convictions, and poorer economic prospects compared to their peers with high self-esteem (Trzesniewski, et al., 2006). Risk factors for low self-esteem have also been identified. Females generally have lower self-esteem compared to males and those from lower socioeconomic backgrounds have lower self-esteem compared to those from higher socioeconomic backgrounds (Dukes, \& Martinez, 1994; McClure, Tanski, Kingsbury, Gerrard, \& Sargent, 2010).

Previous research suggests that adolescents with ASD tend to have lower self-esteem compared to their typically developing peers (Williamson et al., 2008). We suggest that this might be because typically developing children are able to demonstrate their ability to understand other peoples' perspectives from very early in childhood (Howlin, Baren-Cohen \& Hadwin, 1999). However, children with ASD have difficulties with perspective taking (Baron-Cohen, Leslie, \& Frith, 1985). This is merely speculation and evidence to substantiate the link between perspective taking, ASD, and self-esteem is needed.

\section{Happiness}

For the purposes of this study happiness and wellbeing will be used interchangeably, though it is acknowledged that there are some differences in the definitions of these constructs (Raibley, 2012). Measures of happiness vary in the literature. Some researchers use a singleitem question to assess subjective happiness; "In general, I am happy with how things are for me in my life now" (Burton, \& Phipps, 2008). Other researchers use a longer standardized self-report questionnaires with multiple questions (e.g., the happiness and satisfaction subscales of the Piers-Harris Children's Self-Concept Scale (Piers \& Herzberg, 2002). Differences in the measurement of happiness aside, being happy in childhood is important because children who are happy tend to go on to be happier adults (Freeman, Templer, \& Hill, 1999) and they also tend to have better academic outcomes (Quinn, \& Duckworth, 2007). Being happy is also associated with better relationships and interactions with the surrounding people, which can be an area of impairment for children with ASD (APA, 2013). Happy children have better relationships and feel more connected with their parents and peers (Dunn, \& Bennett, 2007; Guhn, Schonert-Reichl, Gadermann, Hymel, \& Hertzman, 2013; Holder, \& Coleman, 2009). Being with friends is associated with higher levels of happiness compared to being alone (Csikszentmihalyi \& Hunter, 2003). In general, children who are highly social, as indicated by a sociable temperament, are happier (Holder \& Klassen, 2010). Higher levels of happiness are also found in children who have better educated parents and have a higher family income (Burton et al., 2008; Gudmundsdottir et al., 2016).

\section{Prosociality}

Prosocial behaviors are voluntary actions with the intention of benefiting another person (Eisenberg \& Fabes, 1998), and as with self-esteem and happiness they can be measured in a variety of ways. Measuring prosocial behaviors can be done using peer-report, where in some cases the child's peers nominate those who "are friendly towards lots of other kids", and who "help other kids the most" (Griese \& Buhs, 2014). Alternatively, the child reports how often they have been in receipt of a supportive act by a peer (Martin \& Huebner, 2007). Self-reports are also used to measure child's own levels of prosociality towards other children with statements such as "I will invite bystanders to join in a game", and "I comfort a person who is crying" (Markiewicz, Doyle \& Brendgen, 2001). Parents and/or teachers may also comment on the child's levels of prosociality using the Strengths and Difficulties Questionnaire (SDQ, Goodman, 1997). The SDQ has previously been used to measure prosociality in children with ASD and other developmental difficulties (Russell, Rodgers, \& Ford, 2013; Toseeb, McChesney, \& Wolke, 2018; Toseeb, Pickles, Durkin, Botting, \& Conti-Ramsden, 2017; Toseeb \& St Clair, under review). 
Prosocial behaviors emerge very early in infancy (Liszkowski, Carpenter, \& Tomasello, 2008; Warneken \& Tomasello, 2007). Some research studies suggest that there is a level of stability in prosociality during middle childhood (Cote, Tremblay, Nagin, Zoccolillo, \& Vitaro, 2002; Flynn, Ehrenreich, Beron, \& Underwood, 2014) but other studies find that there is a modest decrease in prosociality (Kokko, Tremblay, Lacourse, Nagin, \& Vitaro, 2006) or even a modest increase (Toseeb \& St. Clair, under review). Children who are prosocial are more popular amongst their peers (Asher \& Coie, 1990; Zimmer-Gembeck, Geiger, \& Crick, 2005), have better quality friendships (Markiewcz, Doyle, \& Brendgen, 2001), and are less likely to manifest antisocial and delinquent behaviors (Carlo et al., 2014; Pursell, Laursen, Rubin, Booth-LaForce, \& Rose-Krasnor, 2008). Taking part in prosocial peer interactions appears to provide support for children who have negative experiences (such as victimisation) by facilitating coping and psychosocial resilience (Griese et al., 2014; Martin et al., 2007). Being male (Hay \& Pawlby, 2003) or from a low socioeconomic background have been identified as some of the risk factors for lower levels of prosocial behavior (Guinote, Cotzia, Sandhu, \& Siwa, 2015; Piff, Kraus, Cote, Cheng, \& Keltner, 2010). Given that many of the correlates of prosociality are in the domain of relationships with others, an area of weakness for children with ASD (APA, 2013), prosociality may be an area of concern for these children.

Many of the factors that are associated with happiness, self-esteem, and prosociality are linked to social relationships and social functioning, an area of concern for children with ASD (APA, 2013). There is also evidence to suggest that, in typically developing samples, self-esteem is positively associated with prosociality and with happiness (Baumeister, Campbell, Krueger, \& Vohs, 2003; Zuffiano et al., 2014). Therefore, in the present study, we wanted to examine the co-occurrence of happiness, self-esteem, and prosociality when children with and without ASD were 11 years old. Identifying sub-groups of children who share common patterns across all three constructs allowed us to compare the associations between children with ASD who have optimum positive functioning compared to those with suboptimum positive functioning. Latent class analysis (LCA) was chosen as the most appropriate method to identify such patterns of co-occurrence. This personcentered approach seeks to identify whether sub-groups of children display similar patterns of positive functioning across multiple domains. This study was motivated by three main research questions:

1. What are the different patterns of co-occurrence of happiness, self-esteem, and prosociality in a population sample of children with and without ASD?
2. Are children with ASD more or less likely to belong to a particular sub-group of happiness, self-esteem, and prosociality when compared to their peers without ASD?

3. Which factors are associated with positive functioning in children with ASD?

\section{Method \\ Study Sample}

The Millennium Cohort Study (MCS) is a multidisciplinary study that follows the lives of approximately 19,000 children born in the UK between the years 2000-2001. Data was accessed via the UK Data Service (http://www.ukdataservice.ac.uk/). The MCS sample was randomly selected from UK electoral wards, with the application of disproportionate stratification in order to provide an adequate representation of all four areas of the UK (England, Scotland, Wales, Northern Ireland), including deprived areas and areas with a high concentration of ethnic minority families. The first data sweep was carried out when the children were 9 months old. At the time of this present analysis, six data sweeps were available: children were sampled when they were aged 9 months $(N=18,522), 3$ years $(N=15,590)$, 5 years $(N=15,246), 7$ years $(N=13,857)$, 11 years $(N=13,287)$, and 14 years old $(N=11,726)$. Data was collected from primary caregivers and the children on an extensive range of information, including areas covering parenting, cognitive development, education, and socioeconomic status. Full details of the MCS, including methodological information, is reported elsewhere (Connelly \& Platt, 2014). Data used in this paper were collected from cohort members (the children) and the primary caregiver, who was usually a parent.

This cross-sectional analysis made use of data collected when the child was 11 years old. In a number of cases, more than one child per household was surveyed. Only one child per family was included in the analyses undertaken here. The total sample size used for our analyses was 13,285 (6,710 males and 6,575 females). The total sample was split into two groups, children with ASD and children without ASD. There were no significant differences in gender $(P=0.41)$, socioeconomic status $(P=0.93)$, and ethnicity $(P=0.75)$ between those children who took part aged 11 years old and those who took part aged 9 months but not 11 years old.

The sample of children with ASD was determined using the process previously described by Dillenburger, Jordan, McKerr, and Keenan (2015). During parental interviews carried out when the child was 5, 7, and 11 years old, the primary caregiver was asked "Has a doctor or health professional ever told you that [child] has Autism, Asperger's 
syndrome or autistic spectrum disorder?" Children whose parents answered affirmatively to the question at least one of the three time points were included in the sample of "children with ASD". This yielded a sample size of 408 children. The mean age of children with ASD was 10.67 years ( $\mathrm{SD}=0.49$ years), of which $79 \%$ were male.

The remainder of the total sample will be subsequently referred to as "children without ASD". The sample size of children without ASD was 12,877, of which $50 \%$ were male. The mean age was 10.68 years $(\mathrm{SD}=0.48$ years $)$.

\section{Measures of Happiness, Self-Esteem, and Prosociality}

Happiness. Self-report was used to measure happiness. Indicators of subjective well-being that were used in the MCS had previously been used in the Youth Panel of the British Household Panel Survey (BHPS), which began in 1991 (University of Essex, 2010). The happiness scale was constructed as an additive to the well-being scales used in the BHPS (Chan \& Koo, 2011). Participants were asked 6 questions and responded on a 7-point scale $(1=$ completely happy to $7=$ not at all happy). These responses were recoded so that the scale ranged from 0 to 6 and then reverse scored to avoid counterintuitive interpretation. The questions were "How do you feel about your school work?", "How do you feel about the way you look?", "How do you feel about your family?", "How do you feel about your friends?", "How do you feel about the school that you go to?", and "How do you feel about your life as a whole?". The responses were summed to create a happiness score (range 0-42). A higher sum score indicated higher levels of happiness. The internal consistency was acceptable for the happiness scale (Cronbach's alpha for children with $\mathrm{ASD}=0.79$ and children without $\mathrm{ASD}=0.83$ )

Self-esteem. Participants were asked to complete a shortened version of the Rosenberg Self-Esteem scale (Rosenberg, 1965). They were asked to respond on a 4point scale $(0=$ strongly disagree to $3=$ strongly agree). The statements were "On the whole, I am satisfied with myself", "I feel that I have a number of good qualities", "I am able to do most things as well as most other people do", "I am a person of value", and "I feel good about myself". The responses were summed to form a self-esteem score (range 0-15). Higher scores indicated higher levels of self-esteem. Scores of 7 or lower were taken to indicate low self-esteem. The internal consistency was acceptable for the self-esteem scale (Cronbach's alpha for children with $\mathrm{ASD}=0.73$ and children without $\mathrm{ASD}=0.74$ ).

Prosociality. The prosocial subscale of the parentreport Strengths and Difficulties Questionnaire (SDQ) (Goodman, 1997) was used to measure prosociality. The primary caregiver was asked to respond to 5 statements about the child on a scale ranging from 0 to $2(0=N o t$ true, 1 = Somewhat true, and 2 = Certainly true). The statements were "Considerate of other people's feelings", "Shares readily with other children", "Helpful if someone is hurt, upset or feeling ill", "Kind to younger children", and "Often volunteers to help others". The sum scores for the subscale ranged from 0 to 10 . The clinical cutoff for low prosociality is a sum score of 4 or lower. A score of 5 is considered borderline. A score of 6 or higher is considered normal. The prosociality cutoff scores used in this study are supported in the literature (Goodman, Meltzer, \& Bailey, 1998). The internal consistency was acceptable for the prosociality sub-scale (Cronbach's alpha for children with ASD $=0.79$ and children without ASD $=0.64)$.

\section{Additional Measures}

Socioeconomic status (SES). A measure of household income was used to determine SES. The UK government's poverty 'threshold' of $60 \%$ of median household income (Department for Work \& Pensions, 2014) was used. Low SES were defined as those children whose family income was below this threshold.

Communication problems. The primary caregiver reported their child's communication problems when the child was 11 years old. Children were considered to have a communication problem if the primary caregiver endorsed that their child had one of the following; a stammer or a stutter, another problem with talking, or a problem understanding other people.

Emotional difficulties. The parent-report SDQ was used to measure emotional difficulties. The primary caregiver was asked to respond to 5 statements about their child on a scale ranging from 0 to $2(0=$ Not true, $1=$ Somewhat true, and $2=$ Certainly true). The statements were "gets a lot of headaches, stomach aches or sickness", "worries a lot", "often unhappy, downhearted or tearful", "nervous in new situations", and "many fears, easily scared". Sum scores for the subscale ranged from 0 to 10 . A score of 3 or lower is considered normal, 4 is borderline, and 5 or higher is considered abnormal. For this study, a score of 4 or higher was considered clinical impairment (Goodman et al., 1998). The internal consistency was acceptable for the emotional difficulties subscale (Cronbach's alpha for children with ASD $=0.77$ and children without ASD =0.69).

Peer problems. The parent-report SDQ was used to measure peer problems. The primary caregiver was asked to respond to 5 statements about their child on a scale 
ranging from 0 to $2(0=$ Not true, $1=$ Somewhat true, and 2 = Certainly true). The statements were "usually on his/ her own", "other children or young people pick on him/ her", "gets on better with adults than people his/her age". Two of the statements were reverse scored, "one good friend or more", and "other people their age generally like him/her". Sum scores for the subscale ranged from 0 to 10. A score of 2 or lower is considered normal, 3 is borderline, and 4 or higher is considered abnormal. For this study, a score of 3 or higher was considered clinical impairment (Goodman et al., 1998). The internal consistency was acceptable for the peer problems subscale (Cronbach's alpha for children with ASD $=0.75$ and children without ASD $=0.60)$.

Conduct problems. The parent-report SDQ was used to measure conduct problems. The primary caregiver was asked to respond to 5 statements about the child on a scale ranging from 0 to $2(0=$ Not true, $1=$ Somewhat true, and 2 =Certainly true). The statements were "gets very angry and often loses temper", "fights a lot", "often accused of lying or cheating", "takes things that are not theirs". One statement was reverse scored, "usually does as he/she is told". Sum scores for the subscale ranged from 0 to 10 . A score of 2 or lower is considered normal, 3 is borderline, and 4 or higher is considered abnormal. For this study, a score of 3 or higher was considered clinical impairment (Goodman et al., 1998). The internal consistency was acceptable for the conduct problems sub-scale (Cronbach's alpha for children with ASD $=0.69$ and children without ASD $=0.61$ ).

Hyperactivity. The parent-report SDQ was used to measure hyperactivity. The primary caregiver was asked to respond to 5 statements about their child on a scale ranging from 0 to $2(0=$ Not true, $1=$ Somewhat true, and 2 = Certainly true). The statements were "restless, cannot stay still for long", "constantly fidgeting or squirming", "easily distracted". Two of the items were with reverse scored: "thinks before doing things" and "finishes work he/she is doing". Sum scores for the subscale ranged from 0 to 10 . A score of 5 or lower is considered normal, 6 is borderline, and 7 or higher is considered abnormal. For this study, a score of 6 or higher was considered as clinical impairment (Goodman et al., 1998). The internal consistency was acceptable for the hyperactivity subscale (Cronbach's alpha for children with ASD $=0.80$ and children without ASD =0.79).

Secondary Data Analysis

The MCS data was accesed from the UK Data Service (http://www.ukdataservice.ac.uk/). The Centre for Longitudinal Studies at the Institute of Education
(University College London), the UK Data Archive, and the UK Data Service bear no responsibility for the analysis or interpretation of these data.

\section{Statistical Analyses}

Statistical analyses were conducted using Mplus version 7.3 (Muthen \& Muthen, 2012) and IBM SPSS 23 (IBM Corp, 2015). All values are reported to 2 decimal places, except percentages, which are reported as whole numbers, and significance values, which are reported to up to 3 decimal places. Weighted means are reported throughout the paper unless otherwise specified. Independent samples t-tests were carried out to determine if there were any significant differences between children with and without ASD for levels of happiness, selfesteem, and prosociality.

Latent Class Analysis (LCA) was run to determine if there were meaningful groups of children sharing similar patterns of positive functioning. The total scores from the three scales (happiness, self-esteem, \& prosociality) were standardized before running the LCA. The fit of five models was assessed (two-class to six-class). The most parsimonious model was assessed with the Akaike Information Criterion (AIC; Akaike, 1987), the Bayesian Information Criterion (BIC; Schwarz, 1978), and the sample size-adjusted Bayesian Information Criterion (ssaBIC; Sclove, 1987). Better fitting models are indicated by lower values. A measure of entropy was also used to assess how accurately the children were classified into the chosen model, with higher values (range 0-1) indicating better classification (Celeux \& Soromenho, 1996). Finally, the Lo-Mendell-Rubin adjusted likelihood test (LMR-LRT; Lo, Mendell, \& Rubin, 2001) identified the best model. When a nonsignificant value $(P>0.05)$ is found the model with one less class is then judged as acceptable. The LMR-LRT $P$ value was used to identify the most appropriate number of latent classes, with the other fit stiatistics (AIC, BIC, ssaBIC) supporting this decision. Seventy-five children (60\% male) had missing data for all three positive functioning scales and were not included in the analyses. There were no significant $(P<0.05)$ differences in gender $(P=0.09)$, and ethnicity $(P=0.57)$ between those included in the analysis and those who were missing data on all positive functioning scales. Significant differences were found for those with missing data and socioeconomic status $(P<0.001)$. The final total included and weighted for analysis was 13,210.

After the most parsimonious model was chosen, the children were assigned to the most appropriate class, using the classify-analyse approach (Clogg, 1995), with class membership based on posterior probabilities (Bray, Lanza, \& Tan, 2015). Multivariate multinomial regression models were run to examine predictors of class 
membership in the total sample. Gender, ASD status, and SES were entered as predictor variables, and class membership was used as the outcome variable. The optimum class was used as the baseline class in all comparisons, unless otherwise specified. To investigate the membership of the optimum class in the sample of children with ASD, five univariate multinomial logistic regression models were run. The outcome was always class and the predictors were one of the following: subscales of the SDQ: emotional, peer, conduct, or hyperactivity, or communication difficulties.

\section{Results}

Happiness, Self-Esteem, and Prosociality

Children without ASD were happier $(P<0.001)$, had higher self-esteem $(P<0.001)$, and were more prosocial $(P<0.001)$ when compared with children with ASD. Means, standard deviations, and test statistics are shown in Table 1.

\section{Latent Classes}

The fit indices for the LCA are shown in Table 2. Happiness, self-esteem, and prosociality scores split by class are shown in Table 3. The most parsimonious model was the 5-class solution, which is shown in Figure 1. The "very low prosociality class" (7\%) was characterized by children who were happy and had high self-esteem but they were not prosocial. This class had the lowest levels of prosociality across all classes and the participants on this class were on the borderline of clinical impairment. The "low happiness class" (3\%), the class with the fewest children, included those children who had moderate self-esteem and were prosocial but they were the least happy. Children in the "low to moderate positive functioning class" (6\%) were moderately happy and had the lowest self-esteem but they were prosocial. The "moderate to high positive functioning class" (23\%) was characterized by children who were happy, had moderate self-esteem, and were very prosocial. The majority of children were classified into the "optimum class" (61\%). These children were very happy, had high self-esteem, and were very prosocial.

\section{Class Membership by Gender, ASD, and SES}

As shown in Table 4, the rates of class membership varied according to gender and ASD status. For children without ASD, the majority were in the optimum class

Table 1. Group Differences in Happiness, Self-Esteem, and Prosociality

\begin{tabular}{|c|c|c|c|c|c|c|c|}
\hline & Scale & $\begin{array}{l}\text { Children without } \\
\text { ASD mean (SD) }\end{array}$ & $\begin{array}{l}\text { Children with } \\
\text { ASD mean (SD) }\end{array}$ & $t$ & $d f$ & $\begin{array}{c}\text { Mean difference } \\
{[95 \% \mathrm{CI}]}\end{array}$ & Cohen's $d$ \\
\hline Happiness & $0-42$ & $35.74(6.36)$ & $33.01(7.14)$ & $7.04^{* * *}$ & 361 & $2.73[1.97,3.48]$ & 0.35 \\
\hline Self-esteem & $0-15$ & 11.98 (2.15) & $11.26(2.56)$ & $4.99 * * *$ & 339 & $0.71[0.43,0.99]$ & 0.26 \\
\hline Prosociality & $0-10$ & $8.86(1.47)$ & $6.92(2.45)$ & $15.59 * * *$ & 398 & $1.94[1.70,2.19]$ & 0.62 \\
\hline
\end{tabular}

$* * * P<0.001$

Table 2. Latent Class Analysis Fit Statistics (2 Class to 6 Class Solutions)

\begin{tabular}{|c|c|c|c|c|c|c|}
\hline Classes & Log-likelihood & AIC & $\mathrm{BIC}$ & Sample size adjusted BIC & Entropy & Likelihood ratio test $(P)$ \\
\hline 2 & -50106.34 & 100232.68 & 100307.58 & 100275.80 & 0.91 & $5570.73(0.00)$ \\
\hline 3 & -48356.58 & 96741.17 & 96846.01 & 96801.52 & 0.85 & $3409.69(0.00)$ \\
\hline 4 & -47266.07 & 94568.13 & 94702.93 & 94645.72 & 0.84 & $2125.05(0.00)$ \\
\hline 5 & -46685.03 & 93414.05 & 93578.80 & 93508.89 & 0.80 & $1132.25(0.00)$ \\
\hline 6 & -46199.17 & 92450.33 & 92645.04 & 92562.41 & 0.81 & $946.78(0.11)$ \\
\hline
\end{tabular}

AIC, Akaike Information Criterion; BIC, Bayesian Information Criterion.

The chosen model is shown in bold font.

Table 3. Happiness, Self-Esteem, and Prosociality Scores by Class

\begin{tabular}{lcccc}
\hline & $\begin{array}{c}\text { Very low } \\
\text { prosociality class } \\
(N=969)\end{array}$ & $\begin{array}{c}\text { Low happiness } \\
\text { class } \\
(N=421)\end{array}$ & $\begin{array}{c}\text { Low to moderate positive } \\
\text { functioning class } \\
(N=776)\end{array}$ & $\begin{array}{c}\text { Moderate to high positive } \\
\text { functioning class } \\
(N=3000)\end{array}$ \\
\hline Happiness (0-42) & 36.49 & 12.43 & 24.65 & 32.54 \\
Self-esteem (0-15) & 12.01 & 10.99 & 8.87 & 39.10 \\
Prosociality (0-10) & 5.15 & 8.53 & 8.00 & 10.45 \\
\hline
\end{tabular}

Values are mean (standard deviation). 


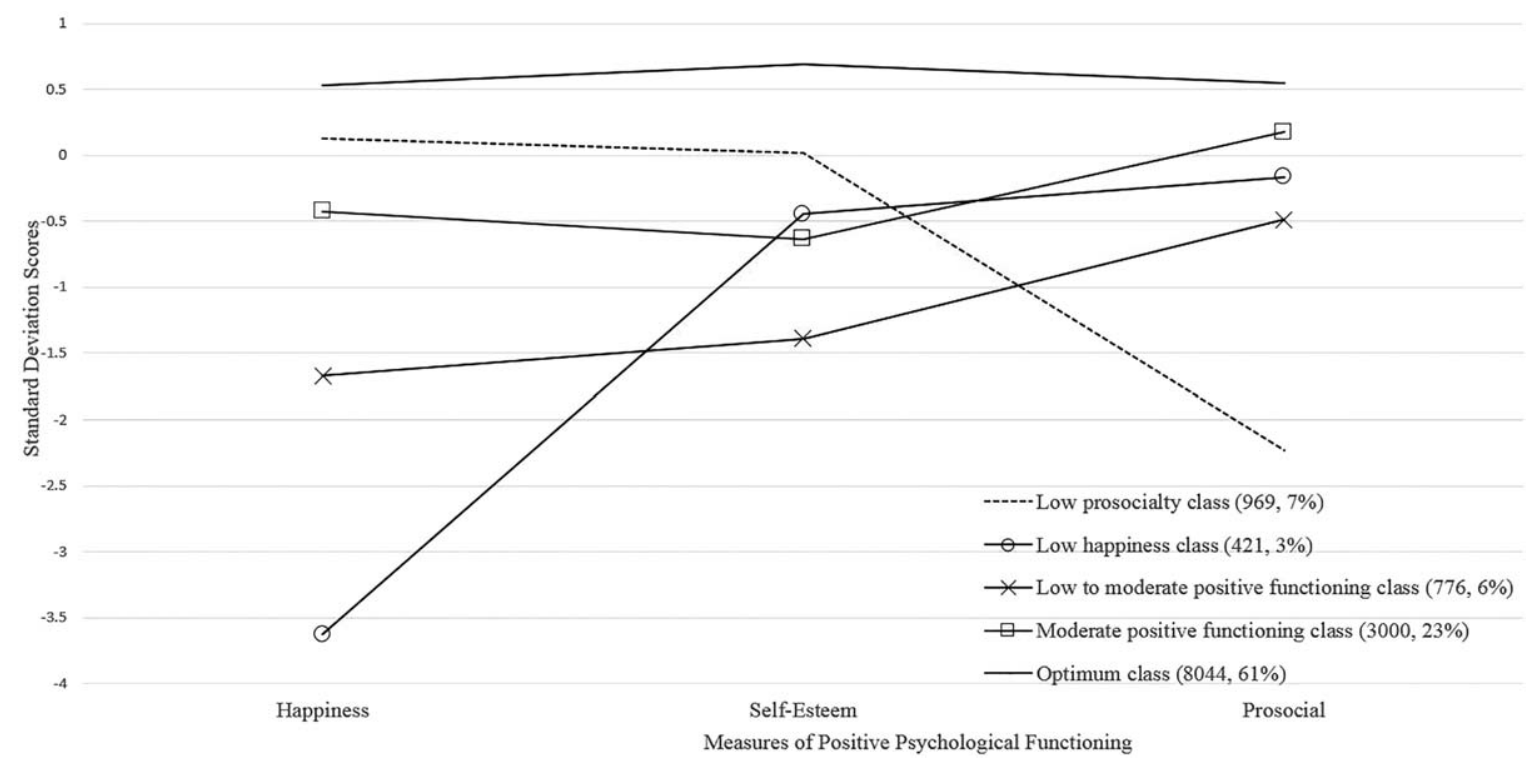

Figure 1. Happiness, self-esteem, and prosociality by class membership.

Table 4. Class Membership Frequencies $\left(n=13210^{a}\right)$

\begin{tabular}{|c|c|c|c|c|c|c|}
\hline & $\begin{array}{c}\text { Very low } \\
\text { prosociality class }\end{array}$ & $\begin{array}{l}\text { Low } \\
\text { happiness class }\end{array}$ & $\begin{array}{c}\text { Low to moderate } \\
\text { positive functioning } \\
\text { class }\end{array}$ & $\begin{array}{c}\text { Moderate to high } \\
\text { positive functioning } \\
\text { class }\end{array}$ & Optimum class & Totals \\
\hline Total sample & $969(7 \%)$ & $421(3 \%)$ & $776(6 \%)$ & $3000(23 \%)$ & $8044(61 \%)$ & $13210(100 \%)$ \\
\hline Males & $650(10 \%)$ & $231(4 \%)$ & $390(6 \%)$ & $1480(22 \%)$ & $3914(59 \%)$ & $6665(100 \%)$ \\
\hline Females & $319(5 \%)$ & $190(3 \%)$ & $386(6 \%)$ & $1520(23 \%)$ & $4130(63 \%)$ & $6545(100 \%)$ \\
\hline Children without ASD & $840(7 \%)$ & $408(3 \%)$ & $711(6 \%)$ & $2932(23 \%)$ & $7918(62 \%)$ & $12809(100 \%)$ \\
\hline Males & $541(9 \%)$ & $219(3 \%)$ & $342(5 \%)$ & $1426(23 \%)$ & $3820(60 \%)$ & $6348(100 \%)$ \\
\hline Females & $299(5 \%)$ & $189(3 \%)$ & $369(6 \%)$ & $1506(23 \%)$ & $4098(63 \%)$ & $6461(100 \%)$ \\
\hline Children with ASD & $129(32 \%)$ & $13(3 \%)$ & $65(16 \%)$ & $68(17 \%)$ & $126(31 \%)$ & $401(100 \%)$ \\
\hline Males & $109(34 \%)$ & $12(4 \%)$ & $48(15 \%)$ & $54(17 \%)$ & $94(30 \%)$ & $317(100 \%)$ \\
\hline Females & $20(24 \%)$ & $1(1 \%)$ & $17(20 \%)$ & $14(17 \%)$ & $32(38 \%)$ & $84(100 \%)$ \\
\hline
\end{tabular}

Values represent $n(\%) . \%$ are rounded to the nearest whole number.

${ }^{a}$ Missing data for 75 participants (68 general population and 7 children with ASD) were not included in LCA, therefore $n=13210$.

$(62 \%)$, whilst the fewest were in the low happiness class (3\%). The children with ASD exhibited a different pattern of positive functioning. The highest proportion was in the very low prosociality class (32\%) but there were approximately an equal number (31\%) in the optimum class. Similar to children without ASD, the lowest proportion of children with ASD was also in the low happiness class (3\%).

As shown in Table 5, after controlling for ASD and socioeconomic status, males were nearly twice as likely to be in the very low prosociality class compared to females. Moreover, after controlling for gender and socioeconomic status, children with ASD were more than twice as likely to belong to the low prosociality class and more likely to be in the low to moderate positive functioning class, when compared to children without ASD. After controlling for gender and ASD status, children in the low prosociality were more likely to be of low socioeconomic status and less likely to be in the moderate to high positive functioning class compared to children of high socioeconomic status.

\section{Class Membership in Children with ASD}

As shown in Table 6, children with ASD in the very low prosociality class were around three to five times more likely to have clinical impairment in emotional difficulties, peer problems, conduct problems, and hyperactivity compared to those children with ASD in the optimum class. They were also around three times more likely to have communication problems compared to the children in the optimum class. Moreover, children with ASD in the low to moderate functioning class were three to five times more likely to have peer problems, conduct problems, and hyperactivity at the level of clinical 
Table 5. Covariates Predicting Latent Class Membership (Multinomial, Full Sample)

\begin{tabular}{|c|c|c|c|c|}
\hline & Very low prosociality class & Low happiness class & $\begin{array}{l}\text { Low to moderate positive } \\
\text { functioning class }\end{array}$ & $\begin{array}{l}\text { Moderate to high positive } \\
\text { functioning class }\end{array}$ \\
\hline \multicolumn{5}{|l|}{ Gender } \\
\hline Male & $1.84^{* * *}(1.51-2.23)$ & $0.99(0.78-1.27)$ & $0.76^{* *}(0.62-0.94)$ & $0.97(0.87-1.08)$ \\
\hline Female & $b$ & $b$ & $b$ & $b$ \\
\hline \multicolumn{5}{|l|}{ ASD } \\
\hline Children with ASD & $2.25^{* * *}(1.49-3.40)$ & $1.54(0.55-4.32)$ & $1.69 *(1.10-2.59)$ & $0.95(0.63-1.43)$ \\
\hline Children without ASD & $b$ & $b$ & $b$ & $b$ \\
\hline \multicolumn{5}{|l|}{ Socioeconomic status } \\
\hline Low socioeconomic status & $1.35^{* *}(1.08-1.68)$ & $1.00(0.70-1.44)$ & $1.14(0.89-1.46)$ & $0.86^{*}(0.74-1.00)$ \\
\hline High socioeconomic status & $b$ & $b$ & $b$ & $b$ \\
\hline
\end{tabular}

Each class is compared to the baseline (0ptimum class, $N=8044)$ with ' $b$ ' as comparison within variables. Values represent odds ratios (95\% confidence intervals).

${ }^{*} P<0.05 ;{ }^{* *} P<0.01 ; * * * P<0.001$.

Table 6. Covariates Predicting Membership of Class (Univariate, Children with ASD Only)

\begin{tabular}{|c|c|c|c|c|}
\hline & Very low prosociality class & Low happiness class & $\begin{array}{l}\text { Low to moderate positive } \\
\text { functioning class }\end{array}$ & $\begin{array}{l}\text { Moderate to high positive } \\
\text { functioning class }\end{array}$ \\
\hline \multicolumn{5}{|c|}{ Emotional difficulties } \\
\hline Clinical Impairment & $3.28^{* * *}(1.72-6.24)$ & $0.74(0.13-4.09)$ & $1.93(0.95-3.93)$ & $1.90(0.91-3.97)$ \\
\hline Normal & $b$ & $b$ & $b$ & $b$ \\
\hline \multicolumn{5}{|l|}{ Peer problems } \\
\hline Clinical impairment & $5.00 * * *(2.38-10.50)$ & $4.10(0.75-22.30)$ & $5.29 * * *(2.29-12.24)$ & $1.41(0.66-3.00)$ \\
\hline Normal & $b$ & $b$ & $b$ & $b$ \\
\hline \multicolumn{5}{|l|}{ Conduct problems } \\
\hline Clinical impairment & $4.15^{* * *}(2.17-7.92)$ & $3.74(0.76-18.32)$ & $3.30 * *(1.62-6.72)$ & $0.57(0.26-1.25)$ \\
\hline Normal & $b$ & $b$ & $b$ & $b$ \\
\hline \multicolumn{5}{|l|}{ Hyperactivity } \\
\hline Clinical impairment & $2.78^{* *}(1.41-5.46)$ & $13.06^{*}(1.40-122.17)^{\mathrm{a}}$ & $3.68^{* *}(1.71-7.91)$ & $1.09(0.53-2.23)$ \\
\hline Normal & $b$ & $b$ & $b$ & $b$ \\
\hline \multicolumn{5}{|c|}{ Communication problems } \\
\hline Present & $3.05^{* *}(1.61-5.78)$ & $0.72(0.13-3.90)$ & $1.74(0.85-3.57)$ & $2.10(0.99-4.45)$ \\
\hline Absent & $b$ & $b$ & $b$ & $b$ \\
\hline
\end{tabular}

Each class is compared to the baseline (optimum class, $N=126)$ with ' $b$ ' as comparison within variables. Values represent odds ratios ( $95 \%$ confidence intervals).

a $* P<0.05 ; * * P<0.01 ; * * * P<0.001$

${ }^{\mathrm{b}}$ This comparison should be interpreted with caution as there are only 13 children with ASD in the low happiness class.

impairment compared to those children with ASD in the optimum class.

\section{Discussion}

This was the first study to investigate the co-occurrence of happiness, self-esteem, and prosociality in a population-based sample of children with and without ASD. The research questions were (a) what are the different patterns of co-occurrence of happiness, selfesteem, and prosociality in a population sample of children, (b) are children with ASD more or less likely to belong to a particular patterned group of happiness, self-esteem, and prosociality when compared to their peers without ASD, and (c) which factors are associated with positive functioning in children with ASD?
Previous research suggests that, in typically developing samples, self-esteem is associated with prosociality (Zuffiano et al., 2014) and happiness (Baumeister et al., 2003). This was generally borne out and, mostly, children exhibited similarity across the three areas of positive functioning. The subsequent sub-group analyses revealed that not all children have similar patterns across the three areas of positive functioning.

\section{Patterns and Predictors of Class Membership}

Five distinct latent classes were identified and reported in this study. Overall, the findings are encouraging. Most children (optimum and moderate to positive functioning classes) had a good level of positive functioning across the three areas: happiness, self-esteem, and prosociality. A minority of children were in the low to 
moderate positive functioning class, which followed a similar pattern of co-occurrence to the moderate to high positive functioning class, albeit at a lower level. Children in the low to moderate positive functioning class were less likely to be male and more likely to have a diagnosis of ASD compared to children from the optimum class. For 90\% of children, happiness, self-esteem, and prosociality co-occured and were strongly associated.

The two classes that deviated from the general pattern of co-occurrence were the low happiness class and the very low prosociality class. Together they made up $10 \%$ of the total sample. Children in the low happiness class had comparable levels of self-esteem and prosociality to the moderate to high positive functioning class but happiness levels were very low. The composition of this class did not differ to the optimum class in terms of gender, ASD status, and socioeconomic status.

Children in the very low prosociality class had otherwise developing positive functioning (happiness \& selfesteem) but they had impairment at a clinical level for prosociality. Children in this class were nearly twice as likely to be male, more than twice as likely to have a diagnosis of ASD, and more likely to be from a low socioeconomic background. This pattern of class membership is consistent with previous research, which suggests that prosociality is lower in males (Hay et al., 2003) and in children with ASD (Lin, Tsai, Rangel, \& Adolphs, 2012). The findings are not consistent with previous work on socioeconomic status. Children and adults from low socioeconomic backgrounds tend to be more prosocial compared to children from high socioeconomic backgrounds (Guinote et al., 2015). We found that when controlling for ASD status and gender, children from a low socioeconomic background were more likely to be in the very low prosociality class. Such differences may have arisen due to the multivariable approach that we employed that controls for potential confounders.

\section{Class Membership and ASD Status}

The distribution of classes was different for children with and without ASD. Encouragingly, nearly half of children with ASD were in the optimum or moderate to high positive functioning class. That is, they were happy, had good levels of self-esteem, and were prosocial. These findings suggest that adverse outcomes in relation to positive functioning are not inevitable in children with ASD. Future research studies should adopt multivariable approaches to studying positive functioning to allow for individual differences within groups to become apparent.

\section{Low Self-Esteem in Children with ASD}

Children with ASD were more likely than those without ASD to be in the low to moderate positive functioning class, which is characterized by lower levels of happiness and self-esteem. This is in line with previous research, which found that children with ASD have lower levels of self-esteem than those without (Williamson et al., 2008). It should, however, be noted that only $16 \%$ of children with ASD were in the low to moderate positive functioning class. Although this is higher than the $6 \%$ of children without ASD, it supports the notion that the majority of children with ASD have comparable levels of self-esteem to children without ASD.

Although very low levels of happiness alone were not associated with impairment in other areas of functioning, having low levels of happiness with lower selfesteem (low to moderate positive functioning class) was associated with a clinical level of impairment in peer, hyperactivity, and conduct problems in children with ASD. This is in line with previous research in children without ASD, in which low self-esteem was associated with conduct and peer problems (Ha et al., 2008; O'Moore \& Kirkham, 2001; Patchin \& Hinduja, 2010).

\section{Very Low Prosociality in Children with ASD}

It is well known that there is considerable behavioral heterogeneity in children with ASD but typically previous research employs a single variable approach to studying prosociality, which can be simplistic and stigmatizing. We found that less than one third of children with ASD were identified as having low levels of prosociality. The remaining two thirds of children were in classes with prosociality comparable to the general population. These findings suggest that taking into account happiness and self-esteem, prosocial impairment in most children with ASD may not be a foregone conclusion. This may be in contrast to expectations that children with ASD generally exhibit social deficits when compared to their typically developing peers. That said, this finding has been supported by previous research, where no prosocial behavior differences were found between children with ASD and those without (McDonald \& Messinger, 2012). We suggest a number of reasons for this finding. Research has shown that the development of basic prosocial behaviours can vary with age (Hammond \& Brownell, 2015), and that individual differences are heritable (Knafo-Noam, Uzefovsky, Israel, Davidov, \& Zahn-Waxler, 2015). Prosociality in ASD has been typically less studied than other social behaviors such as empathy (Hammond et al., 2015), suggesting that further research is needed to investigate prosociality in children with ASD specifically, given the reasons suggested above, using a multivariable approach to examine diversity in prosocial development. Furthermore, given that a 5-item measure of prosociality was used, it may be that further work is needed to investigate the multifaceted nature of prosociality in children with ASD. 
Membership of the very low prosociality class for children with ASD was associated with clinical impairment in emotional difficulties, peer, hyperactivity, and conduct problems. It may be that being prosocial promotes resilience and is protective against behavioral and emotional difficulties in children with ASD. These findings suggest that interventions targeted at improving prosociality may have a beneficial effect on co-morbid emotional and behavioral problems in children with ASD. Longitudinal studies would be needed to provide evidence for the long-term benefits of prosociality on emotional and behavioral difficulties in children with ASD.

\section{Strengths and Limitations}

A major strength of the research reported here is the large population-based sample. This allowed for accurate estimates of happiness, self-esteem, and prosociality. Studies of clinical populations suffer from issues such as referral bias, which may lead to inaccurate estimates of the reported effects. Whilst the sample size and research design were major strengths of this study, there were some drawbacks that should be considered. The sample of children with ASD was based on parental report, which was not independently validated by the research team and could be a source of error due to false positives. Also, given that children with ASD typically have poorer reading and literacy skills compared to children without ASD, the self-report method may have introduced a source of error into the analyses. This may be the case for those who did not complete the positive functioning scales used in this study and were therefore excluded from the analysis. As previously mentioned, whilst the 75 children who were missing from the data did not significantly differ from the rest of the sample in terms of sex and ethnicity, they did with regards to socioeconomic status. Family income can have a substantial impact upon children, particularly on their abilities and achievement. This is particularly evident if children suffer poverty during their preschool and early school lives resulting in lower rates of school completion (Brooks-Gunn \& Duncan, 1997). This may account for the missing 75 participants who significantly differed economically from their peers. It may also be the case that children with ASD at the lowest level of functioning were not able to complete the questionnaires and so dropped out of the study. As a result, the levels of positive functioning may have been over estimated.

\section{Conclusions}

Our findings demonstrate that, for the majority of children in our sample, happiness, self-esteem, and prosociality co-occur. Furthermore, although, as a group, children with ASD have lower levels of happiness, self-esteem, and prosociality, our sub-group analysis suggests that nearly half of children with ASD are happy, have good levels of self-esteem, and are prosocial. For children with ASD, having very low levels of prosociality is associated with various social and emotional difficulties, which may in turn have a negative effect on other areas of functioning.

\section{Conflict of Interest}

The authors declare that they have no conflict of interest.

\section{References}

Akaike, H. (1987). Factor-analysis and Aic. Psychometrika, 52, 317-332.

American Psychiatric Association (2013). Diagnostic and statistical manual of mental disorders (5th ed.). Arlington, VA: American Psychiatric Publishing.

Asher, S.R., \& Coie, J.D. (1990). Peer rejection in childhood. Cambridge: Cambridge University Press.

Baird, G., Simonoff, E., Pickles, A., Chandler, S., Loucas, T., Meldrum, D., \& Charman, T. (2006). Prevalence of disorders of the autism spectrum in a population cohort of children in South Thames: The special needs and autism project (SNAP). Lancet, 368, 210-215. doi:10.1016/s0140-6736(06)69041-7

Baron-Cohen, S., Leslie, A.M., \& Frith, U. (1985). Does the autistic-child have a theory of mind. Cognition, 21, 37-46. doi:10.1016/0010-0277(85)90022-8

Baumeister, R.F., Campbell, J.D., Krueger, J.I., \& Vohs, K.D. (2003). Does high self-esteem cause better performance, interpersonal success, happiness, or healthier lifestyles?. Psychological Science, 1-44.

Bray, B.C., Lanza, S.T., \& Tan, X. (2015). Eliminating bias in classify-analyze approaches for latent class analysis. Structural Equation Modeling, 22, 1-11.

Brooks-Gunn, J., \& Duncan, G.J. (1997). The effects of poverty on children. The Future of Children, 7, 55-71.

Buescher, A.V.S., Cidav, Z., Knapp, M., \& Mandell, D.S. (2014). Costs of Autism Spectrum Disorders in the United Kingdom and the United States. JAMA Pediatrics, 168, 721-728. doi: 10.1001/jamapediatrics.2014.210

Burton, P., \& Phipps, S. (2008). Economic resources, relative socioeconomic position and social relationships: Correlates of the happiness of young Canadian teens. Child Indicators Research, 1, 350-371. doi:10.1007/s12187-008-9014-6

Carlo, G., Vicenta Mestre, M., McGinley, M.M., Tur-Porcar, A., Samper, P., \& Opal, D. (2014). The protective role of prosocial behaviors on antisocial behaviors: The mediating effects of deviant peer affiliation. Journal of Adolescence, 37, 359-366. doi:10.1016/j.adolescence.2014.02.009

Celeux, G., \& Soromenho, G. (1996). An entropy criterion for assessing the number of clusters in a mixture model. Journal of Classification, 13, 195-212. doi:10.1007/bf01246098 
Chan, T.W., \& Koo, A. (2011). Parenting style and youth outcomes in the UK. European Sociological Review, 27, 385399. doi:10.1093/esr/jcq013

Clogg, C.C. (1995). Latent class models: Recent developments and prospects for the future. In G. Arminger, C. C. Clogg, \& M. E. Sobel (Eds.), Handbook of statistical modeling for the social and behavioral sciences. (pp. 311-359). New York, NY: Plenum Press.

Connelly, R., \& Platt, L. (2014). Cohort profile: UK millenium cohort study (MCS). International Journal of Epidemiology, 43, 1719-1725.

Cote, S., Tremblay, R.E., Nagin, D., Zoccolillo, M., \& Vitaro, F. (2002). The development of impulsivity, fearfulness, and helpfulness during childhood: Patterns of consistency and change in the trajectories of boys and girls. Journal of Child Psychology and Psychiatry and Allied Disciplines, 43, 609618. doi:10.1111/1469-7610.00050

Csikszentmihalyi, M., \& Hunter, J. (2003). Happiness in everyday life: The uses of experience sampling. Journal of Happiness Studies, 4, 15. doi:10.1023/A:1024409732742

Department for Work \& Pensions (2014). Households Below Average Income: An analysis of the income distribution 1994/95 - 2012/13 Retrieved from London: United Kingdom

Dillenburger, K., Jordan, J.A., McKerr, L., \& Keenan, M. (2015). The Millennium child with autism: Early childhood trajectories for health, education and economic wellbeing. Developmental Neurorehabilitation, 18, 37-46. doi:10.3109/ 17518423.2014.964378

Dukes, R.L., \& Martinez, R. (1994). The impact of ethgender on self-esteem among adolescents. Adolescence, 29, 105-115.

Dunn, D.S., \& Bennett, T.W. (2007). The happiness hypothesis: Finding modern truths in ancient wisdom. Journal of Social and Clinical Psychology, 26, 134-136. doi:10.1521/ jscp.2007.26.1.134

Eisenberg, N., \& Fabes, R.A. (1998). Prosocial development. In W. Damon \& N. Eisenberg (Eds.), Handbook of child psychology (Vol.3, pp. 701-778). New York: Wiley.

Flynn, E., Ehrenreich, S.E., Beron, K.J., \& Underwood, M.K. (2014). Prosocial behavior: Long-term trajectories and psychosocial outcomes. Social Development. doi:10.1111/ sode. 12100

Freeman, L.J., Templer, D.I., \& Hill, C. (1999). The relationship between adult happiness and self-appraised childhood happiness and events. Journal of Genetic Psychology, 160, 4654.

Goodman, R. (1997). The Strengths and Difficulties Questionnaire: A research note. J Child Psychol Psychiatry, 38, 581586.

Goodman, R., Meltzer, H., \& Bailey, V. (1998). The strengths and difficulties questionnaire: A pilot study on the validity of the self-report version. European Child \& Adolescent Psychiatry, 7, 125-130.

Green, H., McGinnity, A., Meltzer, H., Ford, T., \& Goodman, R. (2005). Mental health of children and young people in Great Britain, 2004. Retrieved from Basingstoke

Griese, E.R., \& Buhs, E.S. (2014). Prosocial behavior as a protective factor for children's peer victimization. Journal of Youth and Adolescence, 43, 1052-1065. doi:10.1007/ s10964-013-0046-y
Gudmundsdottir, D.G., Asgeirsdottir, B.B., Huppert, F.A., Sigfusdottir, I.D., Valdimarsdottir, U.A., \& Hauksdottir, A. (2016). How does the economic crisis influence adolescents' happiness? Population-based surveys in Iceland in 20002010. Journal of Happiness Studies, 17, 1219-1234. doi: 10.1007/s10902-015-9639-3

Guhn, M., Schonert-Reichl, K.A., Gadermann, A.M., Hymel, S., \& Hertzman, C. (2013). A population study of victimization, relationships, and well-being in middle childhood. Journal of Happiness Studies, 14, 1529-1541. doi:10.1007/ s10902-012-9393-8

Guinote, A., Cotzia, I., Sandhu, S., \& Siwa, P. (2015). Social status modulates prosocial behavior and egalitarianism in preschool children and adults. Proceedings of the National Academy of Sciences of the United States of America, 112, 731-736. doi:10.1073/pnas.1414550112

Gurney, J.G., McPheeters, M.L., \& Davis, M.M. (2006). Parental report of health conditions and health care use among children with and without autism: National survey of children's health. Archives of Pediatrics and Adolescent Medicine, 160, 825-830.

Ha, C., Petersen, N., \& Sharp, C. (2008). Narcissism, self-esteem, and conduct problems evidence from a British community sample of 7-11 year olds. European Child \& Adolescent Psychiatry, 17, 406-413. doi:10.1007/s00787-008-0682-z

Hammond, S.I., \& Brownell, S.A. (2015). Prosocial Development Across the Lifespan. In Tremblay RE, Boivin M, Peters $\mathrm{RDeV}$, eds. Knafo-Noam A, topic ed. Encyclopedia on Early Childhood Development [online]. http://www.child-encyclopedia.com/prosocial-behaviour/according-experts/prosocialdevelopment-across-lifespan. Accessed February 7, 2018.

Harter, S. (2012). The construction of the self: Developmental and sociocultural foundations. New York, USA: The Guilford Press.

Hay, D.F., \& Pawlby, S. (2003). Prosocial development in relation to children's and mothers' psychological problems. Child Development, 74, 1314-1327. doi:10.1111/14678624.00609

Holder, M.D., \& Coleman, B. (2009). The contribution of social relationships to children's happiness. Journal of Happiness Studies, 10, 329-349. doi:10.1007/s10902-007-9083-0

Holder, M.D., \& Klassen, A. (2010). Temperament and happiness in children. Journal of Happiness Studies, 11, 419-439. doi:10.1007/s10902-009-9149-2

Howlin, P., Baron-Cohen, S., \& Hadwin, J. (1999). Teaching children with autism to mind-read: A practical guide. Chichester, England: Wiley.

IBM Corp (2015). IBM SPSS statistics for windows, version 23.0 Armonk, NY: IBM Corp.

Knafo-Noam, A., Uzefovsky, F., Israel, S., Davidov, M., \& ZahnWaxler, C. (2015). The prosocial personality and its facets: Genetic and environmental architecture of mother-reported behavior of 7-year old twins. Frontiers in Psychology, 6, 1-9.

Kokko, K., Tremblay, R.E., Lacourse, E., Nagin, D.S., \& Vitaro, F. (2006). Trajectories of prosocial behavior and physical aggression in middle childhood: Links to adolescent school dropout and physical violence. Journal of Research on Adolescence, 16, 403-428. doi:10.1111/j.1532-7795.2006.00500.x

Lin, A., Tsai, K., Rangel, A., \& Adolphs, R. (2012). Reduced social preferences in autism: Evidence from charitable 
donations. Journal of Neurodevelopmental Disorders, 4, doi:10.1186/1866-1955-4-8

Liszkowski, U., Carpenter, M., \& Tomasello, M. (2008). Twelvemonth-olds communicate helpfully and appropriately for knowledgeable and ignorant partners. Cognition, 108, 732739. doi:10.1016/j.cognition.2008.06.013

Lo, Y., Mendell, N.R., \& Rubin, D.B. (2001). Testing the number of components in a normal mixture. Biometrika, 88, 767-778. doi:10.1093/biomet/88.3.767

Markiewcz, D., Doyle, A.B., \& Brendgen, M. (2001). The quality of adolescents' friendships: Associations with mothers' interpersonal relationships, attachments to parents and friends, and prosocial behaviors. Journal of Adolescence, 24, 429-445. doi:10.1006/jado.2001.0374

Martin, K.M., \& Huebner, E.S. (2007). Peer victimization and prosocial experiences and emotional well-being of middle school students. Psychology in the Schools, 44, 199-208. doi:10.1002/pits.20216

Matson, J.L., \& Nebel-Schwalm, M.S. (2007). Comorbid psychopathology with autism spectrum disorder in children: An overview. Research in Developmental Disabilities, 28, 341-352. doi:10.1016/j.ridd.2005.12.004

McClure, A.C., Tanski, S.E., Kingsbury, J., Gerrard, M., \& Sargent, J.D. (2010). Characteristics associated with low selfesteem among US adolescents. Academic Pediatrics, 10, 238-244.

McDonald, N.M., \& Messinger, D.S. (2012). Empathic responding in toddlers at risk for an autism spectrum disorder. Journal of Autism and Developmental Disorders, 42, 15661573.

Moksnes, U.K., \& Espnes, G.A. (2012). Self-esteem and emotional health in adolescents-gender and age as potential moderators. Scandinavian Journal of Psychology, 53, 483489. doi:10.1111/sjop.12021

Muthen, L.K., \& Muthen, B.O. (2012). Mplus user's guide (7th ed.). Los Angeles: California.

O'Moore, M., \& Kirkham, C. (2001). Self-esteem and its relationship to bullying behaviour. Aggressive Behavior, 27, 269-283. doi:10.1002/ab.1010

Orth, U., \& Robins, R.W. (2014). The development of selfesteem. Current Directions in Psychological Science, 23, 381-387. doi:10.1177/0963721414547414

Oyane, N.M., \& Bjorvatn, B. (2005). Sleep disturbances in adolescents and young adults with autism and asperger syndrome. Autism, 9, 83-94.

Patchin, J.W., \& Hinduja, S. (2010). Cyberbullying and selfesteem. Journal of School Health, 80, 614-621. doi:10.1111/ j.1746-1561.2010.00548.x

Piers, E.V., \& Herzberg, D.S. (2002). Manual for the Piers-Harris childrens self-concept scale (2nd ed.). Los Angeles: Western Psychological Services.

Piff, P.K., Kraus, M.W., Cote, S., Cheng, B.H., \& Keltner, D. (2010). Having less, giving more: The influence of social class on prosocial behavior. Journal of Personality and Social Psychology, 99, 771-784. doi:10.1037/a0020092

Pursell, G.R., Laursen, B., Rubin, K.H., Booth-LaForce, C., \& Rose-Krasnor, L. (2008). Gender differences in patterns of association between prosocial behavior, personality, and externalizing problems. Journal of Research in Personality, 42, 472-481. doi:10.1016/j.jrp.2007.06.003
Quinn, P.D., \& Duckworth, A.L. (2007). Happiness and academic achievement: Evidence for reciprocal causality. Paper presented at the Annual meeting of the Association for Psychological Science, Washington, DC.

Raibley, J.R. (2012). Happiness is not well-being. Journal of Happiness Studies, 13, 1105-1129. doi:10.1007/s10902-011-9309-Z

Ricciardelli, L.A., \& Yager, Z. (2016). Adolescence and body image: From development to preventing dissatisfaction. Oxon, England: Routledge.

Robins, R.W., Donnellan, M.B., Widaman, K.F., \& Conger, R.D. (2010). Evaluating the link between self-esteem and temperament in Mexican origin early adolescents. Journal of Adolescence, 33, 403-410. doi:10.1016/j.adolescence.2009.07.009

Robins, R.W., Hendin, H.M., \& Trzesniewski, K.H. (2001). Measuring global self-esteem: Construct validation of a single item measure and the Rosenberg self-esteem scale. Personality and Social Psychology Bulletin, 27, 151-161.

Robins, R.W., Trzesniewski, K.H., Tracy, J.L., Gosling, S.D., \& Potter, J. (2002). Global self-esteem across the life span. Psychology and Aging, 17, 423-434. doi:10.1037//08827974.17.3.423

Rosenberg, M. (1965). Society and the adolescent self-image. Princeton, NJ: Princeton University Press.

Russell, G., Rodgers, L.R., \& Ford, T. (2013). The strengths and difficulties questionnaire as a predictor of parent-reported diagnosis of autism spectrum disorder and attention deficit hyperactivity disorder. PLoS One, 8, e80247. https://doi. org/10.1371/journal.pone.0080247.

Schwarz, G. (1978). Estimating the dimension of a model. doi: 10.1214/aos/1176344136

Sclove, S.L. (1987). Application of model-selection criteria to some problems in multivariate analysis. Psychometrika, 52, 333-343. doi:10.1007/bf02294360

Trzesniewski, K.H., Donnellan, M.B., Moffitt, T.E., Robins, R.W., Poulton, R., \& Caspi, A. (2006). Low self-esteem during adolescence predicts poor health, criminal behavior, and limited economic prospects during adulthood. Developmental Psychology, 42, 381-390. doi:10.1037/00121649.42.2.38

Toseeb, U., McChesney, G., \& Wolke, D. (2018). The prevalence and psychopathological correlates of sibling bullying in children with and without autism spectrum disorder. Journal of Autism and Developmental Disorders, doi: 10.1007/s10803-018-3484-2

Toseeb, U., Pickles, A., Durkin, K., Botting, N., \& ContiRamsden, G. (2017). Prosociality from early adolescence to young adulthood: A longitudinal study of individuals with a history of language impairment. Research in Developmental Disabilities, 62, 148-159. https://doi.org/10.1016/j.ridd. 2017.01.018.

Toseeb, U., \& St Clair, M.C. (under review) Trajectories of prosociality in children with and without expressive language delay at school entry

University of Essex. Institute for Social and Economic Research. (2010). British Household Panel Survey: Waves $1-$ 18, 1991-2009. [data collection]. 7th Edition. UK Data Service. SN: 5151, http://doi.org/10.5255/UKDA-SN-5151-1

van Steensel, F.J.A., Bogels, S.M., \& Perrin, S. (2011). Anxiety disorders in children and adolescents with autistic spectrum disorders: A meta-analysis. Clinical Child and Family 
Psychology Review, 14, 302-317. doi:10.1007/s10567-0110097-0

Warneken, F., \& Tomasello, M. (2007). Helping and cooperation at 14 months of age. Infancy, 11, 271-294.

Williams, G., Sears, L.L., \& Allard, A. (2004). Sleep problems in children with autism. Journal of Sleep Research, 13, 265-268.

Williamson, S., Craig, J., \& Slinger, R. (2008). Exploring the relationship between measures of self-esteem and psychological adjustment among adolescents with Asperger Syndrome. Autism, 12, 391-402. doi:10.1177/1362361308091652
Zimmer-Gembeck, M.J., Geiger, T.C., \& Crick, N.R. (2005). Relational and physical aggression, prosocial behavior, and peer relations-Gender moderation and bidirectional associations. Journal of Early Adolescence, 25, 421-452. doi: $10.1177 / 0272431605279841$

Zuffiano, A., Alessandri, G., Kanacri, B.P.L., Pastorelli, C., Milioni, M., Ceravolo, R., ... Caprara, G.V. (2014). The relation between prosociality and self-esteem from middleadolescence to young adulthood. Personality and Individual Differences, 63, 24-29. doi:10.1016/j.paid.2014.01.041 